\title{
Histological, histochemical and fine structure studies of the lacrimal gland and superficial gland of the third eyelid and their significance on the proper function of the eyeball in alpaca (Vicugna pacos)
}

\author{
J. Klećkowska-Nawrot ${ }^{1}$, R. Nowaczyk ${ }^{1}$, K. Goździewska-Harłajczuk ${ }^{1}$, K. Krasucki ${ }^{2}$ \\ M. Janeczek ${ }^{1}$ \\ ${ }^{1}$ Department of Animal Physiology and Biostructure, Faculty of Veterinary Medicine, University of Environmental \\ and Life Sciences, Wroclaw, Poland \\ ${ }^{2}$ Department of Descriptive and Clinical Anatomy, Medical University of Warsaw, Poland
}

[Received 19 August 2014; Accepted 6 November 2014]

\begin{abstract}
The lacrimal gland (LG) and superficial gland of the third eyelid (SGTE) belong to accessory organs of the eye. The aim of the present studies was to evaluate the histological, histochemical and fine structure of the LG and SGTE obtained from 3 adult females and 2 adult males of alpaca (Vicugna pacos). The LG was situated in the dorsolateral angle of the orbit between the dorsal rectus and the lateral rectus muscles. The SGTE was located between the medial rectus muscle, the ventral rectus muscle and was partially covered by the ventral oblique muscle of the eyeball. There were no effect of gender on the morphometry of examined LG and SGTE. The third eyelid resembles an anchor in shape. During histological and ultrastructural analyses using light and transmission electron microscopy, it was established that the LG and SGTE are tubulo-acinar glands with mucoserous characters. The LG contains either lymphocytes or plasma cells, while SGTE had rare plasma cells and numerous lymphocytes in connective tissue. The cartilage of the third eyelid was composed of hyaline tissue. Numerous aggregations of lymphocytes as lymph nodules in bulbar surface of the third eyelid were observed. The LG and SGTE secretory cells exhibited a similar ultrastructure appearance in electron microscopic examination, with secretory cells tightly filled with intracytoplasmatic secretory granules and numerous clusters of mucus of different sizes which were observed in the peripheral cells compartment. (Folia Morphol 2015; 74, 2: 195-205)
\end{abstract}

Key words: alpaca, lacrimal gland, superficial gland of the third eyelid, morphological study, local immunological response

\section{INTRODUCTION}

The lacrimal gland (LG) and superficial gland of the third eyelid (SGTE) belong to eye accessory organs [33,
34]. The LG in mammals and avians has multilobular, tubulo-acinar structure. The role of these glands is to secrete serous, mucous or seromucous fluids as

Address for correspondence: J. Klećkowska-Nawrot, PhD, Department of Animal Physiology and Biostructure, Faculty of Veterinary Medicine, University of Environmental and Life Sciences in Wroclaw, ul. Kożuchowska 1/3, 51-631 Wrocław, Poland, tel: +48 713205743 , fax: +48 713205741 , e-mail: lestat_v@poczta.onet.pl 
a part of one among three layers of tear film which is also called the precorneal film [19, 39]. This film is composed of 3 layers: first layer is an oily layer produced by the tarsal (Meibom's) gland, by sebaceous (Zeis's) gland and by ciliary (Moll's) gland. The second layer - aqueous layer - is produces by the accessory (Krause's and Wolfring's) lacrimal glands and LG [17, 19]. The third layer is a mucin layer produced by goblet cells of the conjunctiva (Manz's glands), crypts of Henle and SGTE $[17,19]$. The function of LG affects mainly the production of the aqueous layer that is the thickest and major constituent of the precorneal tear film $[2,16,45]$. The aqueous layer contains several soluble antimicrobial factors that protect the ocular surface [8]. The LG has seromucous character of secretion in Artiodactyla, Carnivora, Insectiovora, Lagomorpha, Perissodactyla, Primates and Rodentia [2]. Martin et al. [27] reported that the canine LG has numerous plasma cells and lymphocytes in the gland interstitium. LG contains a high concentration of lysozyme, which can digest bacterial cells walls, and a gamma globulin protein fraction which also contributes to the antibacterial property of tears [39]. The LG plays an important role in the protection of the cornea and the conjunctiva from drying up and also nourishes and lubricates the eye, contributes in metabolite exchange, protects the cornea surface from injuries caused by foreign bodies, and has bactericidal and bacteriostatic properties $[3,4,30,48,49]$. According to Dartt [7], the tear film consists of water, electrolytes and proteins.

The SGTE arises as a fold in the ventromedial aspect of the conjunctiva. This gland is present among Artiodactyla, Carnivora, Insectiovora, Lagomorpha, Marsupials, Perissodactyla and Primates [2]. SGTE has a tubulo-acinar structure and produces a secretion of mucoalbuminous character $[9,19,40]$. SGTE encircles a crossbar of third eyelid, where numerous lymph nodules are present on the underside of third eyelid $[3,39]$. The third eyelid is also described as plicas semilunaris conjuncitve [33, 34]. The role of the third eyelid is mechanical protection of the cornea, as well as local immunological protection by substances which are present in lymphoid nodules and by tear film distribution on the corneal surface [19, 25]. The movement of the third eyelid in animals has a passive character, which is connected with the lack of muscles actively moving the eyelid [3]. However in birds, the movement of the third eyelid is active, which is associated with the presence of two eyelid muscles ( $m$. quadratus membranae nictitantis et m. pyramidalis membranae nictitantis) [33].

The morphological studies of the LG and SGTE in alpaca (Vicugna pacos) have not been described in the literature to the author's knowledge. Only Purdy [37] performed the detailed studies by using an ophthalmoscope, which concerned only eye disease in these animals. Besides, previous results demonstrated that alpaca rarely shows the signs of partial damage of the eye, until the moment when the vision in both eyes is severely compromised. An additional hazard, which may also affect increase in the prevalence of eye diseases, is a small gene pool of alpacas. Even more essential is to know the proper structure of the LG and SGTE which is important to the proper functioning of the eye.

The aim of this paper is to describe the histological, histochemical and fine structure of the LG, SGTE and third eyelid in alpaca and to compare the results of our research with previous studies in other animal's species.

\section{MATERIALS AND METHODS}

The LG and SGTE samples were obtained from 3 adult females (body weight $49-58 \mathrm{~kg}$ ) and 2 adult males (59 kg and $64 \mathrm{~kg}$ of body weight) of alpacas (Vicugna pacos). Research material came from the Wroclaw Zoological Garden (2 females), and from the own Department's of Animal Anatomy collection (1 female and 2 males). This material was obtained as a result of natural death of animals. It was compatible with Polish law, because for using of post mortem tissues in this study the permission of Ethic Commission is not necessary. For morphology description of LG and SGTE the characteristic methods in topographic anatomy, holotopy and syntopy, were used. The macroscopic study was conducted with stereoscopic Zeiss Stemi 2000-C microscope (Carl Zeiss, Jena, Germany). Morphometric measurements of glands were conducted by using an electronic slide calliper with an accuracy of $0.1 \mathrm{~mm}$. Data were statistically processed by statistical software (Microsoft Office Professional Plus 2010, Microsoft Corporation, Redmond, WA, USA).

\section{Histological analysis}

The samples of the LG and SGTE for histological study were directly fixed in $4 \%$ buffered formaldehyde, rinsed in running water for $24 \mathrm{~h}$, then the material was processed in vacuum tissue processor - ETP 
(RVG3, INTELSINT, Villbasse, Turin, Italy), embedded in paraffin wax and cut on sliding microtome Slide 2003 (Pfm A.g., Köln, Germany) into 3-4 $\mu$ m sections. Then samples were stained with haematoxylin and eosin (H\&E), Masson-Goldner and aldehyde fuchsin methods to demonstrate the general structure. In addition, the methyl green-pyronin $Y$ method [20] was used for the demonstration of plasma cells.

\section{Histochemical analysis}

The histochemical analysis was conducted in order to identify the presence of neutral glycoproteins, glycolipids and phospholipids (periodic acid-Schiff staining - PAS), acid sulfated mucins and sialomucins (Alcian blue pH 2.5 staining $-\mathrm{AB}$ pH 2.5), sulfated and carboxylated acid mucopolysaccharides (Hale's dialysed iron - HDI and aldehyde fuchsin AF stainings). All obtained slides were examined by using Zeiss Axio Scope A1 light microscope (Carl Zeiss, Jena, Germany) applying Axio Vision Release 4.8.2 SP2 programme for histological and histochemical description. PAS, AB pH 2.5, AF and HDI staining's scoring system was based on standard protocol described previously [44].

\section{Transmission electron microscopic analysis}

The collected material (LG and SGTE) was fixed in $2.5 \%$ glutaraldehyde on a $0.1 \mathrm{M}$ phosphate buffer of $\mathrm{pH} 7.4$ and rinsed in a phosphate buffer. The material was then postfixed in $4 \%$ OsO4 for $2 \mathrm{~h}$. After re-rinsing in a phosphate buffer, the fragments of the glands were dehydrated in an acetone series (from $30 \%$ to $100 \%$ ). The dehydrated material was immersed in Epon 812 epoxide resin. The blocks were cut into $70 \mathrm{~nm}$ pieces using an MTX ultramicrotome (Leica Microsystem Wetzlar GmbH, Wetzlar, Germany). The preparations were observed through an EVO LS 15 Zeiss (Carl Zeiss, Jena, Germany) transmission electron microscope (TEM).

\section{RESULTS}

\section{Gross anatomy}

The LG was situated in the dorsolateral angle of the orbit between the dorsal rectus and the lateral rectus muscles. It was elongated in shape and light pink in colour. This gland had a convex periorbital surface, and concave intraorbital surface. In gross appearance, it was a uniform, undivided gland. The mean size (length $\times$ width $\times$ thickness with standard deviation [SD]) of the LG was $31.39 \pm 0.7 \mathrm{~mm} \times 0.84 \pm$ $\pm 0.05 \mathrm{~mm} \times 0.46 \pm 0.03 \mathrm{~mm}$ in females and $32.37 \pm$ $\pm 0.6 \mathrm{~mm} \times 0.905 \pm 0.05 \mathrm{~mm} \times 0.42 \pm 0.02 \mathrm{~mm}$ in males, respectively. There was no effect of gender on the morphometry of examined LG.

The SGTE was located between the medial rectus muscle and the ventral rectus muscle, and was partially covered by the ventral oblique muscle of the eyeball. The SGTE was oval in shape. The mean size (length $\times$ width $\times$ thickness with SD) of the SGTE was $24.73 \pm 1.1 \mathrm{~mm} \times 1.605 \pm 0.08 \mathrm{~mm} \times 0.77 \pm$ $\pm 0.1 \mathrm{~mm}$ in females and $25.88 \pm 0.1 \mathrm{~mm} \times 1.63 \pm$ $\pm 0.03 \mathrm{~mm} \times 0.84 \pm 0.1 \mathrm{~mm}$ in males, respectively. There was no effect of gender on the morphometry of examined SGTE.

The third eyelid was composed of cartilage which consists of a lower and an upper branch and a crossbar. The third eyelid resembles an anchor in shape. The lower and upper branches of the third eyelid cartilage stiffen the fold of the third eyelid, while the crosswise part extends towards the periorbital cone. The crosswise part of the third eyelid was surrounded by the SGTE. The marginal part of the third eyelid was thin and pigmented.

\section{Histological study}

The LG in alpaca was a tubulo-acinar gland with predominance of acini over ducts. It was covered by a thin connective tissue capsule; the adipose tissue was present beneath the capsule. Numerous adipocytes penetrated into the glandular tissue together with the connective tissue and formed thick septa which divided the gland into lobes (Fig. 1A). The capsule and interlobular connective tissue were composed of large number of blood vessels, fibrocytes, lymphocytes and plasma cells (Figs. 1E, 2A), but also collagenous and elastic fibres which were detected in aldehyde fuchsin staining method. The acini (serous cells) were composed of tall conical cells with irregular, chinky lumen, surrounded by basal, myoepithelial cells. The secretory cells' nuclei were big and oval in shape and concentrated in their basal part. These cells have basophilic granular and vacuolated cytoplasm. The tubules were composed of one layer of cubic cells with large lumen and eosinophilic cytoplasm. These tubules have oval nuclei located in the basal areas in the cells (Fig. 1C).

The SGTE was surrounded by thin connective tissue capsule which divided the gland structure on slightly visible lobes. Under the connective tissue capsule, the layer of adipose tissue and blood vessels were located. 


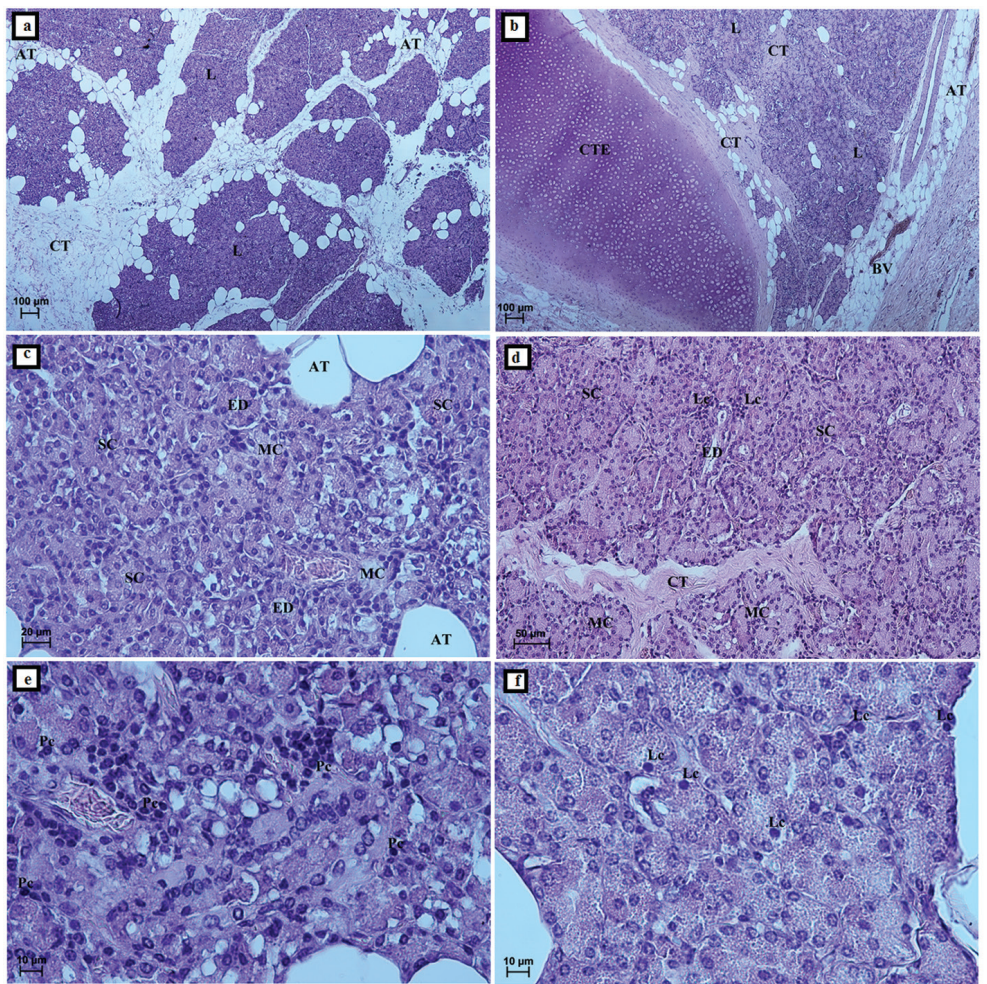

Figure 1. Light micrograph of lacrimal gland (A, Bar $=100 \mu \mathrm{m} ; \mathbf{C}, \mathrm{Bar}=20 \mu \mathrm{m} ; \mathbf{E}, \mathrm{Bar}=10 \mu \mathrm{m})$ and superficial gland of the third eyelid $(\mathbf{B}, \mathrm{Bar}=$ $=100 \mu \mathrm{m} ; \mathbf{D}$, Bar $=50 \mu \mathrm{m} ; \mathbf{F}$, Bar $=10 \mu \mathrm{m})$ of alpaca; H\&E stain; AT — adipose tissue; BV blood vessels; CT — connective tissue; CTE — cartilage of third eyelid; ED - excretory duct; L — lobus; Lc — lymphatic cells; MC mucous cells; Pc — plasma cells; SC serous cells.
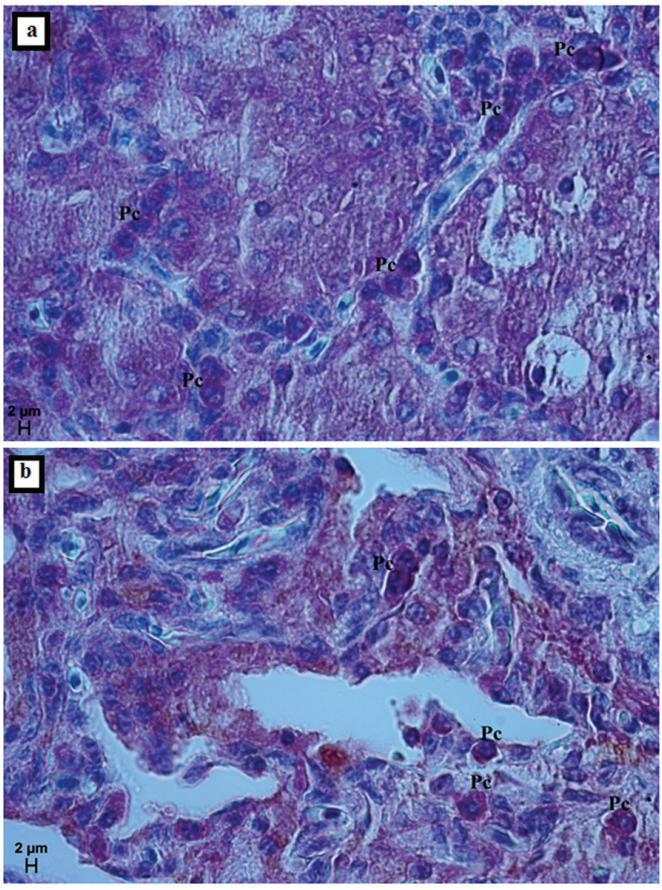

Figure 2. Light micrograph of lacrimal gland (A, Bar $=2 \mu \mathrm{m})$ and superficial gland of the third eyelid (B, Bar $=2 \mu \mathrm{m}$ ) of alpaca, MGP Y stain; Pc — plasma cells.

Inside of the thin connective septa single adipose cells or small aggregations of these cells were observed (Fig. 1B). Among the interlobular connective tissue, numerous lymphocytes and rare plasma cells were found (Figs. 1F, 2B). The SGTE had also a tubulo-acinar structure. The acini were composed of two types of cells. The prevailing cells were serous secretory tall conical cells referred to as type 1 . The acini had basophilic granular and vacuolated cytoplasm with rounded nuclei located close to the base of the cells. The second type of cells was not numerous in comparison with the first type of cells, and crescent-shaped patches of mucous tubule cells, surrounded by acini serous cells were observed. The mucous cells had eosinophilic granular cytoplasm. The ducts had cubic epithelium with eosinophilic cytoplasm. The nuclei of these cells were oval in shape and located in the central part of the cells (Fig. 1D).

The crossbar of the third eyelid cartilage was surrounded by thick connective tissue which came directly from superficial gland. The cartilage of the third eyelid was composed of hyaline tissue with numerous chondrocytes and small amount of intercellular substance. Chondrocytes which were located deeper had oval shape and were mostly single or in rare isogenic group composed of 2-3 cells (Fig. 3B). The conjunctival surface of third eyelid had non-cornified multilayer epithelium (Fig. 3A). In parabasal membrane many blood vessels were observed (Fig. 3B). Furthermore, connective tissue consisted of numerous blood ves- 

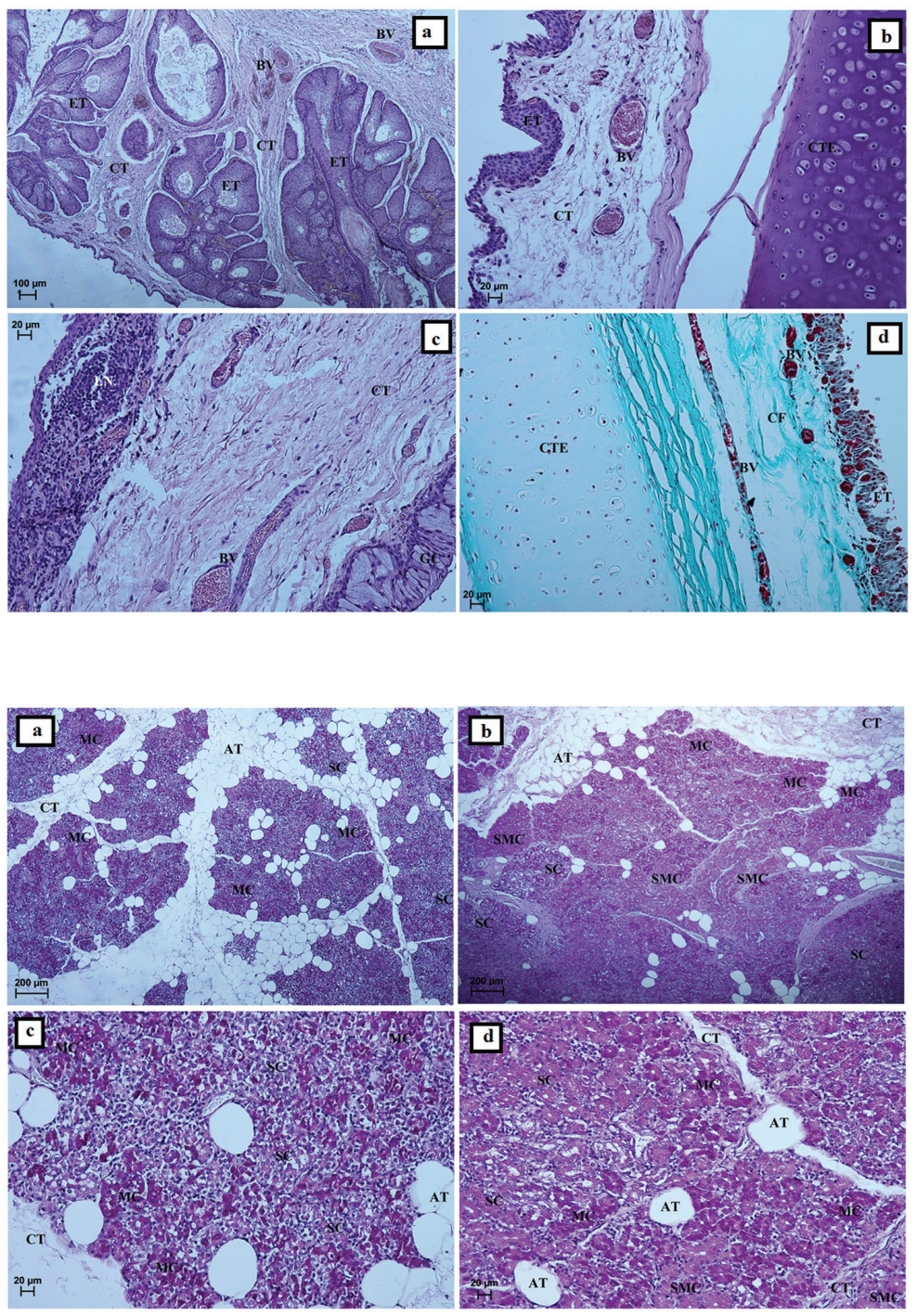

Figure 3. Light micrograph of third eyelid in alpaca, H\&E stain $(\mathbf{A}, \mathbf{B a r}=100 \mu \mathrm{m} ; \mathbf{B}, \mathbf{B a r}=$ $=20 \mu \mathrm{m} ; \mathbf{C}$, Bar $=20 \mu \mathrm{m})$ and Masson-Goldner stain (D, Bar $=20 \mu \mathrm{m})$; BV - blood vessels; CT - connective tissue; CTE - cartilage of third eyelid; ET — epithelium tissue; GC — goblet cells; LN — lymph nodule.

Figure 4. Light micrograph of lacrimal gland (A, Bar $=200 \mu \mathrm{m} ; \mathbf{C}$, Bar $=20 \mu \mathrm{m} ; \mathrm{MC}-$ mucous cells $[+++]$ ) and superficial gland of the third eyelid (B, Bar $=200 \mu \mathrm{m}$; D, Bar $=20 \mu \mathrm{m} ; \mathrm{MC}-$ mucous cells $[++/+++])$ of alpaca; PAS stain; AT — adipose tissue; CT - connective tissue; $\mathrm{SC}$ - serous cells $(-)$; SMC - seromucous cells $(+)$. sels, fibrocytes, elastic and collagen fibres (MassonGoldner stain) (Fig. 3D). The bulbar surface of the third eyelid was covered by non-cornified multilayer epithelium with numerous goblet cells (Fig. 3C). The goblet cells had expanded parabasal part with a high number of secretory granules. In bulbar surface of the third eyelid numerous aggregations of lymphocytes contracting as lymph nodules were observed (Fig. 3C).

\section{Histochemical study}

The LG study with the use of PAS staining showed numerous cells with strong positive reaction containing PAS positive granules $(+++)$; but also cells with average positive reaction $(++)$ or without reaction (-) were observed. PAS staining detected the presence of neutral and acid glycoproteins (Figs. 4A, C). Alcian blue $\mathrm{pH} 2.5$ staining were demonstrated the presence of acid sulfated mucins and sialomucins - mucous cells $(++)$ in the acini and tubules (Fig. 5A). AF staining showed numerous positive granules $(++/+++)$ both in acini and tubules, which evidenced the presence of carboxylated acid mucopolysaccharides (Fig. 5C). Furthermore, the HDI method indicated the small quantity of cells with slightly positive $(-/+)$ or average reactions $(+/++)$, which showed the presence of carboxylated acid mucopolysaccharides in acini and tubules (Figs. 6A, C). Histochemical studies using $\mathrm{AB} \mathrm{pH}$ 2.5, $\mathrm{AF}$ and $\mathrm{HDI}$ revealed that $L G$ in alpaca had mucoserous character of secretion.

The SGTE staining with the PAS method demonstrated the presence of secretory segments of mucous nature, where in more number of cells medium positive reaction was presented $(++)$ while in the smaller group of cells the strong positive reaction $(++/+++)$ was observed. The PAS staining detected the presence 

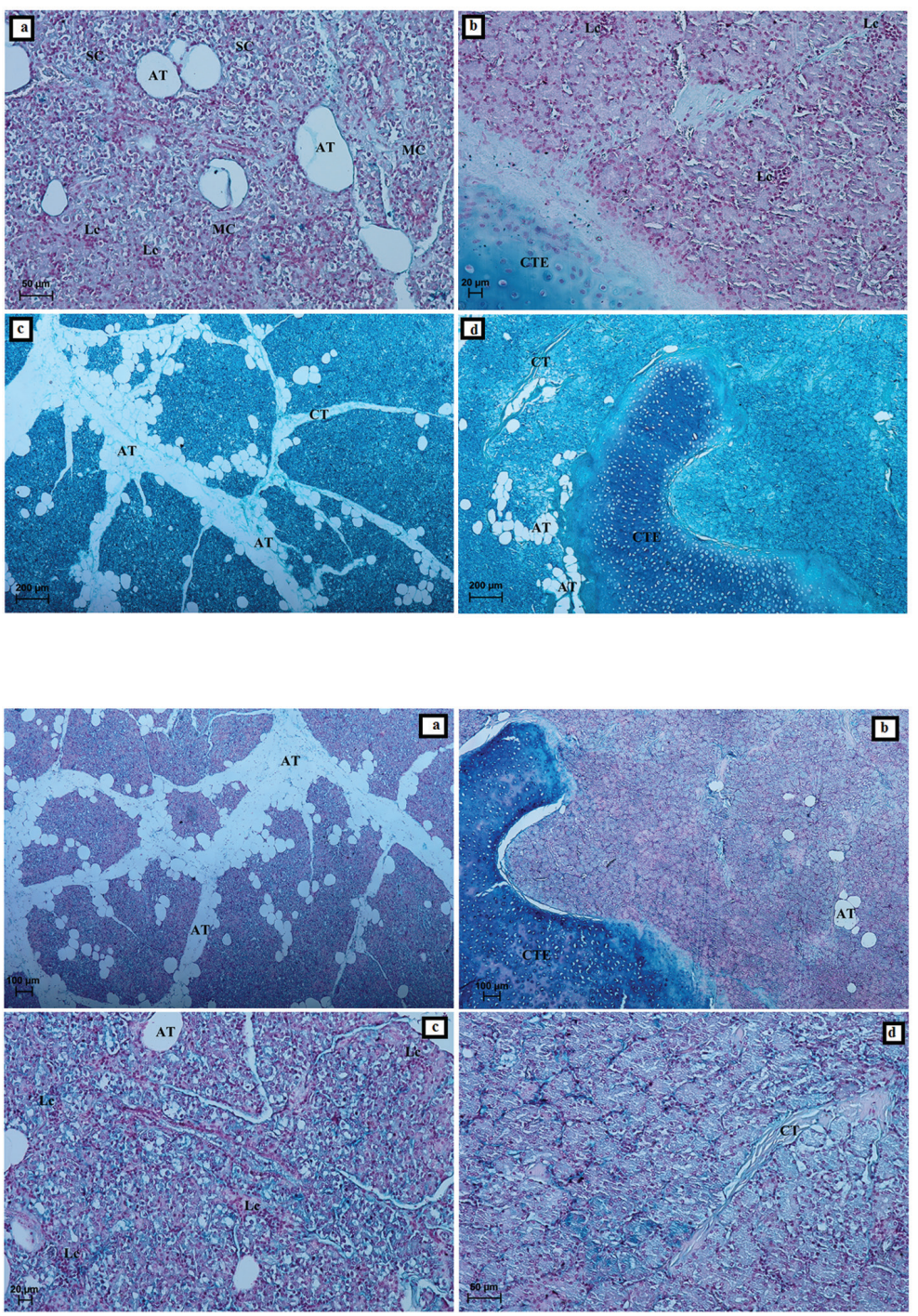

Figure 5. Light micrograph of lacrimal gland (A, Bar $=50 \mu \mathrm{m} ; \mathbf{C}$, Bar $=200 \mu \mathrm{m})$ and superficial gland of the third eyelid (B, Bar $=20 \mu \mathrm{m}$; D, Bar $=200 \mu \mathrm{m}$ ) of alpaca, Alcian blue pH 2.5 stain $(A, B)$ and $A F$ stain $(C, D) ; A T$ - adipose tissue; CT — connective tissue; CTE - cartilage of third eyelid; Lc — lymphatic cells; MC mucous cells; $\mathrm{SC}$ — serous cells.

Figure 6. Light micrograph of lacrimal gland (A, Bar $=100 \mu \mathrm{m} ; \mathbf{C}$, Bar $=20 \mu \mathrm{m})$ and superficial gland of the third eyelid (B, Bar $=100 \mu \mathrm{m}$; D, Bar $=50 \mu \mathrm{m}$ ) of alpaca, HDI stain; AT — adipose tissue; CT — connective tissue; CTE — cartilage of third eyelid; Lc — lymphatic cells. of neutral glycoproteins, glycolipids and phospholipids (Figs. 4B, D). The staining with Alcian blue pH 2.5 method demonstrated the presence of slightly positive granules $(+)$ in mucous cells - which indicated acid sulfated mucins and sialomucins (Fig. 5B). AF staining showed more positive granules $(+++)$ in acini and tubules, which indicated the presence of carboxylated acid mucopolysaccharides (Fig. 5D). HDI stain exhibited mostly light blue cells - slightly positive reaction $(+)$, which indicated seromucous natures of cells. Few places of stronger reaction $(++)$ were visible, which indicated the presence of mucous cells and detected the carboxylated acid mucopolysaccharides (Figs. 6B, D). Histochemical studies with the use of $A B \mathrm{pH}$ 2.5, AF and HDI showed that SGTE in alpaca had mucoserous character of secretion.

\section{Electron microscopic study}

The TEM study showed, that the secretory cells of the LG and SGTE have a similar ultrastructural appearance. The LG and SGTE of alpaca had tubulo-acinar structure and the interlobular trabeculae formed the stroma of these glands. The secretory cells had an ovoid or circular basally located nucleus with an even chromatin pattern and a single nucleolus with nuclear envelope of two distinct membranes around and with clear nuclear pores. The subepithelial region contains plasma cells with cisterns of rough endoplasmic reticulum (RER) (Figs. 7, 8). Numerous large and oval in shape mitochondria with frequent transverse cristae and a dense matrix in cytoplasm were visible. The mitochondria had clear mitochondrial granules (Fig. 9). The mitochondria were associated with cister- 


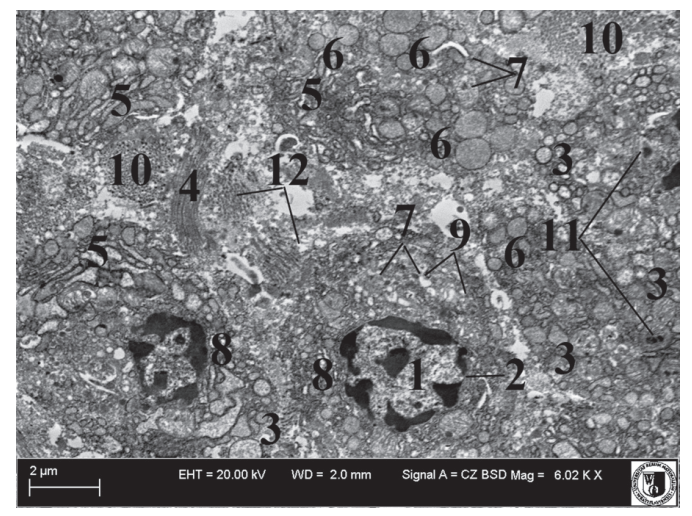

Figure 7. Survey electron micrograph of the lacrimal gland cells in alpaca. Note the presence of numerous large multiple clusters of mucus with different sizes of low electron-dense secretory granules and plasma cells with cisterns of rough endoplasmic reticulum located among the subepithelial region; 1 - nucleus; 2 - nuclear membrane with clear pores; 3 - mitochondria; 4 - microtubule; 5 - diktyosomes of Golgi apparatus; 6 - clusters of mucus; 7 - primary lysosomes; 8 - cisterns of granular endoplasmic reticulum; 9 - cisterns of smooth endoplasmic reticulum; 10 - glycogen granules; 11 - melanin granules; 12 - filaments.

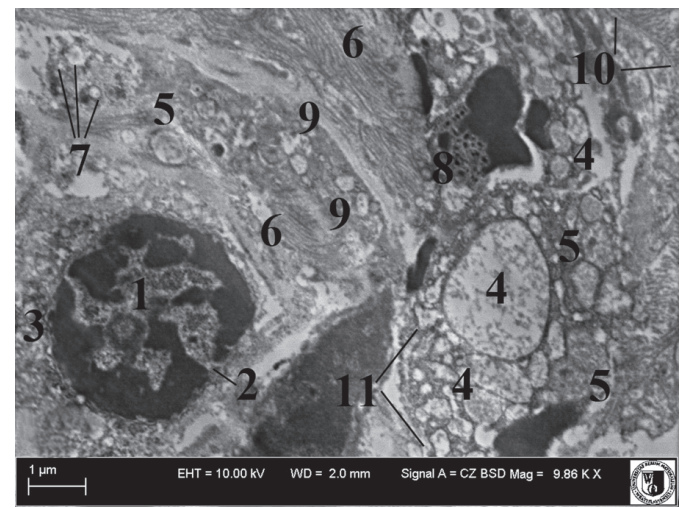

Figure 8. Survey electron micrograph of the superficial gland cells in alpaca. Note the presence of numerous large multiple clusters of mucus with different size and low electron-dense secretory granules and plasma cells with cisterns of rough endoplasmic reticulum located among the subepithelial region. The numerous slightly parallel filament beams and not numerous microtubules can be seen among cytoplasm; 1 - nucleus; 2 - nuclear membrane with clear pores; 3 - cisterns of granular endoplasmic reticulum; 4 clusters of mucus; 5 - mitochondria with visible mitochondrial granules; 6 - filaments; 7 - primary lysosomes; 8 - melanin granules; 9 - secretory granules; 10 - intercellular space; 11 diktyosomes of Golgi apparatus.

nae of RER (Figs. 10, 11). Smooth endoplasmic reticulum was located in peripheral region of each cell and was visible as elongate oval cross-section cytoplasmic membrane. The Golgi complex represented by small lamellae randomly distributed throughout the cytoplasm, each with its own set of vesicles. The secretory

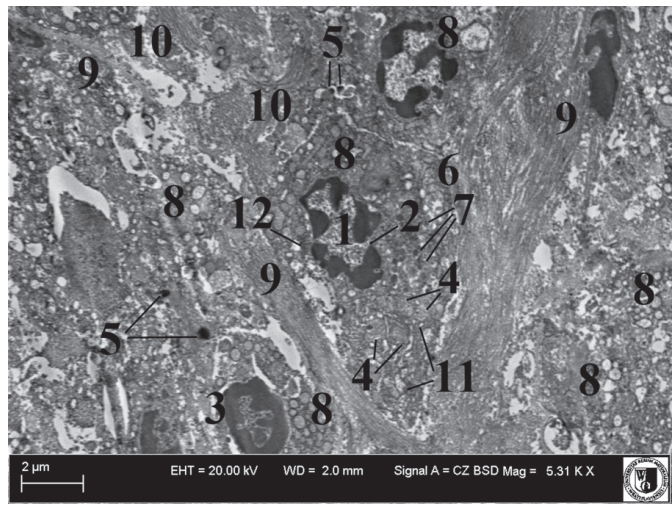

Figure 9. Survey electron micrograph of the superficial gland cells in alpaca. Note the presence of numerous slightly parallel filament beams and not numerous microtubules and numerous macrophages; 1 - nucleus; 2 - nuclear membrane with clear pores; 3 - macrophage; 4 - mitochondria; 5 - melanin granules; 6 - diktyosomes of Golgi apparatus; 7 - primary lysosomes; 8 - secretory granules; 9 - microtubules; 10 - filaments; 11 - smooth endoplasmic reticulum; 12 - glycogen granules.

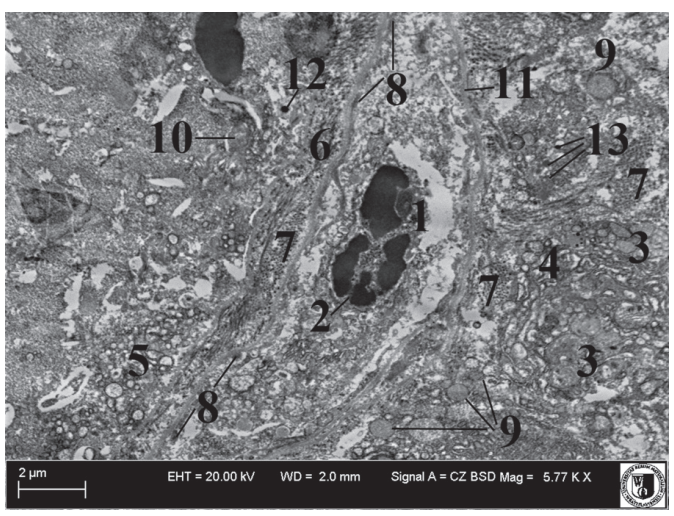

Figure 10. Survey electron micrograph of the lacrimal gland cells in alpaca. Note the presence of numerous glycogen granules, melanin granules in different degrees of maturation, numerous small primary lysosomes and big secondary lysosomes and numerous, big and oval in shape mitochondria with frequent transverse cristae and a dense matrix; 1 - nucleus; 2 - nuclear membrane with clear pores; 3 - mitochondria (numerous); 4 - cisterns of smooth endoplasmic reticulum; 5 - secretory granules; 6 - filaments; 7 - glycogen granules; 8 - hemidesmosomes; 9 - clusters of mucus; 10 - secondary lysosomes; 11 - intercellular space; 12 - melanin granules; 13 - primary lysosomes.

granules which were drop in shape and with different size in cytoplasm were found, and they were limited by membranes (Figs. 7, 9). The Golgi apparatus was filled with quantities of large multiple clusters of mucus of different size and low electron-dense secretory granules (Fig. 7). The most electron-dense granules 


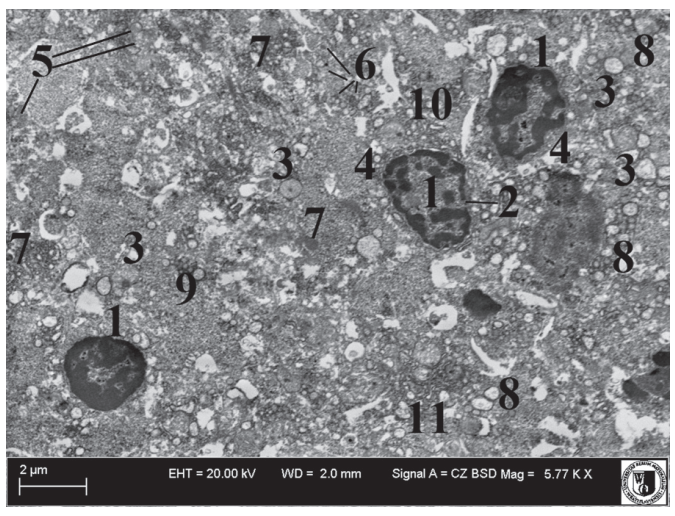

Figure 11. Survey electron micrograph of the superficial gland cells in alpaca. Note the presence of Golgi complex represented by small lamellae randomly distributed throughout the cytoplasm, each with its own set of vesicles and visible as drop in shape, with different size limited by secretory granules membranes; 1 - nucleus; 2 - nuclear membrane with clear pores; 3 - mitochondria with clear mitochondrial granules; 4 - granular endoplasmic reticulum; 5 - high electron density secretory granules; 6 - primary lysosomes; 7 - glycogen granules; 8 - low electron density secretory granules; 9 - secondary lysosomes; 10 - smooth endoplasmic reticulum; 11 - diktyosomes of Golgi apparatus.

were situated in the peripheral regions of each cell. Numerous oval to round granules with contents of moderately to high electron density were seen in the cytoplasm. Moreover, numerous clusters of mucous of different sizes were observed in the peripheral cells compartment (Fig. 7). In the cytoplasm of both glands a lot of glycogen granules, melanin granules in various grades of maturation, numerous small primary lysosomes and big secondary lysosomes with weakly visible membrane and electron dense spherical creations were found (Figs. 7, 8, 10, 11). Near the Golgi apparatus dictyosomes, the prolific of beams parallel slightly filaments and sparse microtubules were present (Figs. 7, 10, 11). Additionally, few lymphocytes and single macrophages were observed (Fig. 9).

\section{DISCUSSION}

The LG and SGTE are responsible for tears secretion [47]. Their impaired function is usually connected with the progress of dry-eye symptoms that results from abnormal, insufficient lubrication of ocular surface, which leads to increased shear forces under the eyelids and diminished ability of the ocular surface to respond to environmental challenges [46].

The dominant gland in mammal eyeballs is LG. The LG in alpaca was situated in the dorsolateral angle of the orbit between of the dorsal rectus and the lateral rectus muscles. It was elongate in shape and was light pink in colour. In gross appearance, it was an uniform, undivided gland, which was different than in Pinard et al. [36] study. Pinard et al. [36] showed that in American bison (Bison bison) and cattle the LG of both species were similar in appearance, with the exception of an accessory lobe in cattle. The main body of LG in American bison and cattle was flattened, oval, pale yellow and lobulated in appearance [36]. Additionally, LG in American bison was longer than in cattle [36]. According to Mohammadpour [29] and Shadkhast and Bigham [42], the LGs in humped camel (Camelus dromedarius) and Iranian River buffalo were elongated, flattened, undivided and irregular in outline. Similar results in sheep and goats were obtained by Shina and Calhoun [43]. Besides of macroscopic examinations, the comparison of gland size in males and females were performed [18, 42]. In our study, there were no differences in LG morphometry between examined animals. It was also showed that there were no distinctions of the size and structure of the gland associated with sexual dimorphism. Similar results were obtained in the morphometric investigations of roe deer, American bison, cattle, and Iranian River buffalo [19, 36, 42]. The LG in examined alpacas, consistently with other research, was clearly divided into a lobes $[2,36,42,43]$. However, previously there was no LG study where interlobular connective tissue had numerous adipocytes, what was observed in alpaca. In American bison and cattle the single sheets of connective tissue septae that encircled each acinar units multiplied and became thicker around the effluent ducts and blood vessels were found [36]. The analysis of microscopic LG structure in alpaca showed a tubulo-acinar gland of mucoserous type with basophilic granules in cytoplasm. The acini were composed of tall conical cells and had irregular, slit-like lumen, while the tubules were composed of one cubic epithelial layer with large lumens. Similar observation has been reported in cattle, Iranian river buffalo, goats and sheep [10, 11, 22, 23, 42, 43]. However, Pinard et al. [36] showed that the cattle LG was a tubulo-acinar gland with eosinophilic granules in cytoplasm. The LG of most species has been described as a compound tubulo-acinar gland with mucoserous nature, e.g. cattle [21, 36], American bison [36], dog [27], goats [43], horses [35], sheep [11, 43], pig [24]. Serous character of LG secretion was shown in roe deer [19] and in goat [22]. The LG secretory components such as neutral and acid glycoproteins (sialylated or sulphated and carboxylated) 
can be revealed by histochemical analysis. According to Spicer and Henson [44], glycoprotein secretory products can be identified with PAS, AB pH 2.5, HDI and AF. Our study showed that alpaca LG produced seromucous secretion. In our research of LG structure the presence of neutral glycoproteins, glycolipids and phospholipids (PAS positive) acid sulfated mucins and sialomucins ( $\mathrm{AB}$ pH 2.5 positive) were found.

The alpaca LG had numerous lymphocytes and rarely plasma cells occurred in connective tissue. According to Aitken and Survashe [1] and Gillete et al. [13], the plasma cells and lymphocytes are a normal cellular constituent of the lacrimal interstitium, but species variability has been reported. The dog is determined to have only single plasma cells or small groups of 5 to 10 plasma cells in the SGTE with more in the LG [27]. Lymphoid cells which were found in the LG are very important in the creation of local immunity in the eye and, due to their ability to secrete immunoglobulins, are also the important protecting factor within the nasopharynx. The activated plasma cells are the source of plasma immunoglobulins protecting the sensitive mucosa and the ocular surface of the eye against diseases, including many upper respiratory diseases in ruminants [7, 31, 38]. Based on Franklin et al. [15] study, the human LG plasma cells are predominantly IgA type and are responsible for the local production of the IgA that is the prevalent immunoglobulin in tears.

The SGTE in alpaca was oval in shape and located between the medial rectus muscle and the ventral rectus muscle, and was partially covered by the ventral oblique muscle of the eyeball. The oval shape of SGTE had also camel and roe deer [19, 30]. Pinard et al. [36] demonstrated that the SGTE in cattle and American bison had a lobulated or cobblestoned appearance. In the bison, gland extended more caudally from the distal edge of the cartilage as compared with cattle. This in turn was reflected in a statistical differences in length, but not in width, between bison and cattle samples [36]. The analysis of the impact of sexual dimorphism on SGTE morphometry showed no differences between alpaca females and males. Similar studies on the impact of gender on the gland morphometry were demonstrated in others species $[19,36$, 42]. Microscopically, the acini of SGTE in alpaca were composed of two types of cells, the prevailing cells were serous secretory tall conical cells referred to as type 1. These cells had a basophilic granular and vacuolated cytoplasm with rounded nuclei located close to the base of the cells. The second type cells, not so numerous as type 1 cells, were crescent-shaped patches of mucous tubule cells, surrounded by acini serous cells. The mucous cells have eosinophilic granular cytoplasm. Similar observations have been reported in American bison and roe deer [19, 36], where as in cattle was reported that the SGTE gland cells were rich in eosinophilic granules [36]. The SGTE is a tubulo-acinar gland producing a secretion of a mucoserous or serous nature in pig, dog, cattle, roe deer, similarly as in camel and bison $[5,12,19,29,36]$. The study of Al-Ramadan and Ali [3] showed that the SGTE in camel had a tubulo-acinar structure with mucous secretion. According to Aldana Marcos et al. [2], the mucus plays a role as protective agent and produces a further reduction in surface tension. Our study has shown, that secretion of SGTE in alpaca had mucoserous character. The presence of neutral glycoproteins, glycolipids and phospholipids (PAS positive) and in a lesser degree of acid sulfated mucins and sialomucins (weakly AB pH 2.5 positive) and carboxylated acid mucopolysaccharides (AF- and HDI-positive) was established. In the interlobular connective tissue of SGTE in alpaca, numerous lymphocytes and small amount of plasma cells were observed. Their participation in the construction of the gland in addition with the lymph nodules of the third eyelid is important in building local eye immunity. The gland of the third eyelid with LG is important in pathogenesis of dry eye also referred to as keratoconjunctivitis sicca, which is a multifactorial disease of the tears and ocular surface that cause discomfort, visual disturbance, and tear film instability, which can potentially damage the ocular surface [26].

Research on the third eyelid are related primarily with its prolapsed and development of conjunctivitis follicularis $[14,50]$. The third eyelid cartilage in the alpaca consisted of the lower and upper branches and a crossbar resembling an anchor. Similar shape of the third eyelid cartilage was observed in pig [12, 41]. In the dog it is T-shaped [6]; however, Schlegel et al. [41] regarded that third eyelid is similar to cone- or crescent-shaped. In small ruminants the third eyelid cartilage looks like a thin rod with a slightly curved form ending in an oval plate; the crossbar is crescent-like [41]. Our study showed that cartilage of the third eyelid was hyaline, which was similar to others research in pig, dog, cattle and small ruminants [18, 32, 41]. However, according to Schlegel et al. [41], in horse the third eyelid has elastic cartilage tissue. 
During TEM investigations similar ultrastructural appearance of the LG and SGTE in alpaca was observed. The LG and SGTE cells contained drop-like secretory granules with different sizes and numerous large multiple clusters of mucous of different sizes and low electron-dense secretory granules. The numerous oval or round granules with contents of moderately to high electron density in the cytoplasm and rarely plasma cells with cisterns of rough endoplasmic reticulum were also observed. According to Klećkowska-Nawrot et al. [19], in roe deer the LG and SGTE secretory cells exhibited a similar ultrastructure appearance, with secretory cells tightly filled with intra cytoplasmic secretory granules. Klećkowska-Nawrot et al. [19] suggested, that the predominantly serous nature of LG in roe deer evoked a strong development of rough endoplasmic reticulum together with excretory granule density. The study by Gargiulo et al. [10] the LG in sheep demonstrated that mucous cells have a rough endoplasmic reticulum which is reduced to a few cisterns located near of the base of cells and along excretory droplets. According to Kühnel [22], the LG in goat had the apical two thirds of the cells occupied by numerous light and dark secretory vacuoles in various stage maturation. On the other hand, in sheep [23] the presence of two different cells types were detected according to size, form and electron density of their granules. Kühnel's [23] ultrastructural study of the canine LG described acinar cells containing only slightly electron-dense granules that had a fine network of strands. In some animals the LG contains melatonin [28]. We observed numerous melatonin granules in alpaca LG and SGTE. Similar results were obtained by Aldana Marcos et al. [2] in Harderian gland, LG and SGTE of armadillo (Chaetophractus villosus) studies. According to Benitez et al. cited by Aldana Marcos et al. [2], the melatonin in the periocular glands of the armadillo is particularly interesting especially if we consider, that in this animal the pineal gland is lacking.

\section{CONCLUSIONS}

Our study as well as further examinations of LG and SGTE glands in toher mammals can bring interesting results what can enlarge knowledge of the physiology and function of the accessory organs of eye.

\section{ACKNOWLEDGEMENTS}

This research was supported by statutory research and development activity founds assigned to Faculty of Veterinary Medicine, Wroclaw University of Environmental and Life Sciences. We are grateful to the Wroclaw zoological garden for release of valuable material for our research.

\section{REFERENCES}

1. Aitken ID, Survashe BD (1977) Plasma cells in vertebrate paraocular glands. In Arch Allergy Appl Immunol, 53: 62-67.

2. Aldana Marcos HJ, Rerrari CC, Cervino C, Affanni JM (2002) Histology, Histochemistry and Fine Structure of the Lacrimal and Nictitans Gland in the South American Armadillo Chaetophractus villosus (Xenarthra, Mammalia). Exp Eye Res, 75: 731-744.

3. Al-Ramadan SY, Ali AM (2012) Morphological studies on the third eyelid and its related structures in the one-humped camel (Camelus dromedarius). J Vet Anat, 5: 71-81.

4. Cabral VP, Laus JL, Zaidan Dagli ML, Pereira GT, Talieri IC, Monteiro ER, Villela Mamede F (2005) Canine lacrimal and third eyelid superficial glands' macroscopic and morphometric characteristics. Ciencia Rural, 35: 391-397.

5. Cazacu P (2010) Researches concerning the morphology of the nictitating gland in dogs. PhD Thesis. IAŞI. 1-7.

6. Constantinescu GM, McClure RC (1990) Anatomy of the orbital fasciae and third eyelid in dogs. Am J Vet Res, 2: 206-263.

7. Dartt DA (2009) Neural regulation of lacrimal gland secretory processes: relevance in dry eye diseases. Prog Retin Eye Res, 28: 155-177.

8. Davidson HJ, Kuonen VJ (2004) The tear film and ocular mucins. Vet Ophthal, 7: 71-77.

9. Ding C, Parsa L, Nandoskar P, Zhao P, Wu K, Wang Y (2010) Duct system of the rabbit lacrimal gland: structural characteristics and role in lacrimal secretion. Invest Ophthalmol Vis Sci, 51: 2960-7.

10. Gargiulo AM, Coliolo P, Ceccarelli P, Pedini V (1999) UItrastructural study of sheep lacrimal gland. Vet Res, 30: 345-351.

11. Gargiulo AM, Dall'Aglio C, Coliolo P, Ceccarelli P, Pedini V (2000) Complex carbohydrate histochemistry and ultracytochemistry of the sheep lacrimal gland. Anat Histol Embryol, 29: 19-23.

12. Getty R (1975) Sisson and Grossmans the anatomy of the domestic animals. W.B. Saunders Company, Philadelphia London Toronto, pp. 1024-1063.

13. Gillette TE, Allansmith MR, Greiner JV, Janusz M (1980) Histologic and immunohistologic comparison of main and accessory lacrimal tissue. Am J Ophthalmol, 89: 724-730.

14. Edelmann ML, Miyadera K, Iwabe S, Komaromy AM (2013) Investigating the inheritance of prolapsed nictitating membrane glands in a large canine pedigree. Vet Ophthalmol, 16: 416-22. 
15. Franklin R, Kenyon K, Tomasi T (1973) Immunohistologic studies of human lacrimal gland: localization of immunoglobulins, secretory component, and lactoferrin. J Immunol, 110: 984-992.

16. Iwamoto T, Jakobiec FA (1990) Lacrimal glands. In: Tasman W ed. Duane's Foundations of Clinical Ophthalmology 1. Lippincott, Philadelphia, PA, USA, pp. 1-21.

17. Jordan D (1990) Accessory lacrimal glands. Ophthalmol Surg, 2: 146-147.

18. Klećkowska-Nawrot J, Dzięgiel P (2007) Morphology of the third eyelid and superficial gland on pig fetuses. Anat Histol Embryol, 36: 428-432.

19. Klećkowska-Nawrot J, K. Marycz K, Czogała J, Kujawa K, Janeczek M, Chrószcz A, Brudnicki W (2013) Morphology of the lacrimal gland and superficial gland of the third eyelid of Roe deer (Capreolus capreolus L.). Pak Vet J, 2: 139-144.

20. Kurnick NB (1955) Pyronin $Y$ in the methyl green-pyronin histological stain. Stain Technol, 30: 213-230.

21. Kühnel W (1968) Vergleichende histologische, histochemische und electronen-mikroskopische Untersuchungen an Tränendrüsen. V. Rind. Zeitsch Zellfor, 87: 504-525.

22. Kühnel W (1968a) Vergleichende histologische, histochemische und electronen-mikroskopische Untersuchungen an Tränendrüsen. II. Ziege. Zeitsch Zellfor, 86: 430-443.

23. Kühnel W (1968b) Vergleichende histologische, histochemische und electronen-mikroskopische Untersuchungen an Tränendrüsen. III. Schaf. Zeitsch Zellfor, 87: 31-45.

24. Kühnel W, Scheele G (1979) On the ultrastructure of the lacrimal gland in pigs. Anat Anz, 145: 87-106.

25. Lavach JD (1990) Large Animal Ophthalmology. The C. V. Mosby Company. St. Louis, Baltimore, Philadelphia, Toronto, pp. 67-69.

26. Li N, Deng X, Gao Y, Zhang S, He M, Zhao D (2013) Establishment of the mild, moderate and severe dry eye models using three methods in rabbits. BMC Ophthalmol, 5: 13: 50. doi: 10.1186/1471-2415-13-50.

27. Martin CL, Munnell J, Kawsan R (1988) Normal ultrastructure and histochemical characteristics of canine lacrimal glands. Am J Vet Res, 49: 1566-1572.

28. Mhatre MC, van Jaarsveld AS, Reiter RJ (1988) Melatonin in the lacrimal gland: first demonstration and experimental manipulation. Biochem Biophys Res Commum, 153: 1186-1192.

29. Mohammadpour AA (2008) Anatomical characteristics of dorsal lacrimal gland in one humped camel (Camelus dromedarius).J Biol Sci, 8: 1104-1106.

30. Mohammadpour AA (2009) Morphological and histological study of superior lacrimal gland of the third eyelid in camel (Camelus dromedarius). Iran J Vet Res, 10: 334-338.

31. Moore CP, Whitley RD (1984) Ophthalmic diseases of small domestic ruminants. Vet Clin North Am Large Anim Pract, 6: 641-665.

32. Nickel R, Schummer A, Seiferle E (2004) Lehrbuch der Anatomie der Haustiere. Band IV. Parey Verlag, Stuttgart, pp. 432-437.

33. Nomina Anatomica Avium (1993) Second edition. Published by the Club. Cambridge Massachusetts.
34. Nomina Anatomica Veterinaria (2012) Fifth edition (revised version). Published by the Editoral Committee. Hannover (Germany) Columbia MO (USA) Ghent (Belgium) Sapporo (Japan).

35. Orlandini G, Bacchi A (1977) Sulla ultrastruttura della ghiandola lacrimale negli equidi. Arch Ital Anat Embriol, 82: 1-20.

36. Pinard CL, Weiss ML, Brightman AH, Fenwick BW, Davidson HJ (2003) Normal Anatomical and histochemical characteristics of the lacrimal glands in the american bison and cattle. Anat Histol Embryol 32: 257-262.

37. Purdy SR (2000) The alpaca eye study. In: Llamas and Alpacas in Colorado, Wyoming, the Rocky Mountains, and Elsewhere [Medline].

38. Rebhun WC (1984) Ocular manifestations of systemic dieases in cattle. Vet Clin North Am Large Anim Pract, 6: 623-639.

39. Reece WO (2009) Functional anatomy and physiology of domestic animals. Chapter 5. The Sensory Organs. 4th Ed. Wiley-Blackwell, lowa, USA

40. Schechter JE, Warren DW, AK Mircheff AK (2010) A lacrimal gland is a lacrimal gland, but rodent's and rabbit's are not human. Ocul Surf, 8: 111-134.

41. Schlegel T, Brehm H, Amselgruber WM (2001) The cartilagine of the third eyelid: A comparative macroscopical and histological study in domestic animals. Ann Anat, 2: 165-169.

42. Shadkhast M, Bigham AS (2010) A Histo-Anatomical study of dorsal lacrimal gland in Iranian river buffalo. Vet Scan, 5: $1-5$.

43. Sinha RD, Calhoun ML (1966) A gross, histologic and histochemical study of the lacrimal apparatus of sheep and goats. Am J Vet Res, 27: 1633-1640.

44. Spicer SC, JG Henson JG (1967) Methods for localizing mucosubstances in epithelial and connective tissue. In: Bajusz E, Jamin F eds. Series on methods and achievements in experimental pathology. Vol. 2. S Karger Press, Basal, pp. 78-112.

45. Stein R, Hurwitz JJ (1996) Anatomy and physiology of tear secretion. In: Hurwitz JJ ed. The lacrimal system. Lippincott-Raven, New York, USA, pp. 1-8.

46. Stern ME, Beuerman RW, Fox Ri, Gao J, Mircheff AK, Pflugfelder SC (1998) The pathology of dry eye: the interaction between the ocular surface and lacrimal glands. Cornea, 17: 584-589.

47. Stern ME, Gao J, Siemasko KF, Beuerman RW, Pflugfelder SC (2004) The role of the lacrimal functional unit in the pathophysiology of dry eye. Exp Eye Res, 78: 409-416.

48. Walde I. et. al. (1998) Afecções do aparelho lacrimal. In: Atlas de clínica oftalmológica do cão e do gato. 2. ed. São Paulo, Manole, pp. 93-104.

49. Zagon IS, Campbell AM, Sassani JW, McLaughlin PJ (2012) Spontaneous episodic decreased tear secretion in rats is related to opioidergic signaling pathways. Invest Ophthalmol Vis Sci, 53: 3234-3240.

50. Zirm M, Schauenstein K, Dimmer H, Daxecker F (1980) Immunological studies on the conjunctivitis follicularis. Klin Monbl Augenheilkd, 176: 70-75. 